\title{
Clinical management of inflammatory bowel disease: Beyond disease activity. I. Assessing psychosocial factors
}

\author{
T Michael VAllis, PhD, Geoffrey K TuRnbull, MD
}

TM VALLIS, GK TURNBUll. Clinical management of inflammatory bowel disease: Beyond disease activity. I. Assessing psychosocial factors. Can J Gastroenterol 1992;6(1):39-43. Inflammatory bowel disease (IBD) is a chronic, relapsing disorder that can be very disabling to the patient and often leads to significant lifestyle problems (eg, emotional distress, social isolation, work impairment and disability). Ayailable evidence strongly indicates that health status is influenced by psychosocial factors as well as disease activity. This is the first of a two-part series, the purpose of which is to provide a framework to guide the gastroenterologist in the assessment and management of psychosocial factors that impact on the health status of the IBD patient. Part I contains a review of existing approaches to assessment of psychosocial factors, which include focusing an psychosomatic or psychiatric factors. The growing body of evidence in support of a 'biopsychosocial' approach to understanding and treating health status is reviewed. In this approach, distress and disability are not seen as due to psychopathology, but stemming directly from the experience of illness itself. Part II will focus on specific strategies to maximize psychosocial adjustment to this disabling illness.

Key Words: Inflammatory bowel disease, Psychiatric illness, Psychosocial factors, Psychosocial treatment, Quality of life

\section{Traitement clinique du syndrome du côlon irritable: Au-delà de l'activité de la maladie. Partie I: Évaluation des facteurs psychosociaux}

RESUME: Le syndrome du côlon irritable (SCI) est une affection chronique et récidivante qui peut être invalidante et perturbe souvent le mode de vie (troubles émotionnels, isolement social, incapacité de travail et invalidité). Les données recueillies indiquent fortement que l'état de santé est aussi influencé par des facteurs psychosociaux que par l'activité de la maladie en soi. Il s'agit de la première étape d'une étude en deux parties. Elle vise à fournir un cadre de travail

Department of Psychology and Department of Medicine, Division of Gastroenterology, Camp Hill Medical Centre and Dalhousie University, Halifax, Nova Scotia

Correspondence and reprints: Dr TM Vallis, Department of Psychology, Camp Hill Medical Centre, 1763 Robie Street, Halifax, Nova Scotia B3H 3 G2

Received for publication August 6, 1991. Accepted January 31, 1992
TNFlammatory BOWEL DISEASE 1 (IBD) is a chronic illness consisting of exacerbations and remissions of disease, with many patients having unpredictable flare-ups. Treatment of IBD is symptomatic, involving medication, diet and other nutritional measures, and surgery. Surgical resections of the bowel in Crohn's disease are used judiciously as relapse after surgery is common. Surgical resection in ulcerative colitis can be curative, but such procedures leave the patient without the large bowel and rectum.

Given that the treatment of IBD is symptomatic, it is understandable that gastroenterologists have been most interested in disease activity in evaluating the experience of IBD patients (1).

A number of reliable rating scales have been developed to index disease activity. For Crohn's disease, these include the Crohn's Disease Activity Index (2) and the Dutch Activity Index by Van Hees et al (3). For ulcerative colitis, the St Mark's Index (4) and the Truelove classification (5) have been developed to index disease activity.

While such scales can be used reliably, questions have recently been raised as to whether disease activity alone is sufficient for assessing and treating IBD patients (1). There are at least two reasons for such questions. First, clinical experience with IBD patients em- 
qui guidera le gastroentérologue dans l'évaluation et la gestion des facteurs psychosociaux qui influent sur l'état de santé du patient porteur du SCI. La première partie passe en revue les approches actuelles d'évaluation de ces facteurs et s'attache plus particulièrement aux aspects psychosomatiques ou psychiatriques. Elle examine les données de plus en plus nombreuses qui militent en faveur d'une approche «biopsychosociale" permettant de mieux comprendre et aborder l'état de santé. Dans cette perspective, les douleurs et l'invalidité ne sont plus attribuées à une psychopathologie, mais semblent directement issues de l'expérience de la maladie elle-même. La deuxième partie s'attachera aux stratégies particulières qui visent à maximiser l'adaptation psychosociale à cette maladie invalidante.

phasizes that illness presentation (eg, distress, physician visits, medication use) is not completely dependent on disease activity. All gastroenterologists have encountered patients who display extreme 'illness behaviour' with little objective disease activity as well as patients with extensive disease activity who display little illness behaviour. Second, research into other chronic medical conditions, such as cardiovascular problems, rheumatoid arthritis, etc, strongly indicates that quality of life issues figure prominently in the illness experience.

Drossman and associates (6-8) have been influential in emphasizing the role of quality of life, and associated psychosocial factors, in the illness experience of IBD patients. Garrett and Drossman (1) reviewed existing disease activity indices and concluded that most of these measures suffer from poor standardization, and are likely to be insufficiently sensitive to all but the most severely ill IBD patients. Since disease activity measures do not strongly predict functional status, Garrett and Drossman suggested that disease activity measures be supplemented with health related quality of life measures to improve the prediction of functional status.

In a series of studies Drossman and colleagues (6-8) collected disease activity, general health and quality of life measures on a sample of IBD patients. Their data indicated that patients experienced social and psychological impairment more than physical impairment. Further, Crohn's disease patients reported a lower quality of life than ulcerative colitis patients, a finding replicated in two studies, one involving a large sample of members of a national association for ileitis and colitis $(6,7)$. Quality of life measures were more strongly correlated with general health status than were disease activity measures, and quality of life measures predicted physician visits independently from disease measures. The reverse was true for predicting hospitalizations and surgeries, where disease activity measures were superior to quality of life measures (8). Collectively, these data are convincing in indicating the need for gastroenterologists to assess quality of life issues in addition to disease activity, since the two factors predict meaningful patient outcomes.

Accepting the need to assess quality of life leaves one with the question of how to conduct such assessments, and how to intervene once assessments are complete. In part I of this two-part series, the authors review a number of approaches to assessment, and identify their strengths and weaknesses. Part II (9) recommends an approach to clinical management which best addresses the complexities common with IBD.

\section{HISTORICAL PERSPECTIVE}

The approach to psychosocial factors as they impact on IBD has evolved through a number of stages over the years. The early psychological approach was characterized by the assumption that the presenting physical symptoms were not true disease-based symptoms, but pseudosymptoms, brought on by underlying psychopathology (eg, repressed psychodynamic conflicts, hypersensitivity to stress) (10-12).

Research attempting to identify personality profiles associated with IBD are based, implicitly or explicitly, on the assumption that personality factors (psychopathology) either cause disease onset, or are responsible for the psychosocial difficulties associated with IBD. Much of this literature is dated, and efforts in this area have been unfruitful $(10,11)$. Ford and colleagues (13) examined a group of Crohn's disease patients and concluded that the typical patient had obsessive compulsive traits, in conjunction with dependency conflicts. They also suggested that these characteristics preceded the development of symptoms (ie, were causal). McKegney and colleagues (12) examined a large sample of IBD patients and concluded that $40 \%$ had psychiatric problems, with character disorders predominating. Other studies have reported frequent psychiatric problems in ulcerative colitis and Crohn's disease patients (14-16).

In contrast, a number of studies ( 10 , 17-21) have not been able to identify a clear personality profile associated with IBD. Gerbert (10) conducted a comprehensive review of psychological factors in Crohn's disease patients, and evaluated a number of personality factors, including dependency, repressed rage and emotional immaturity. No clear personality factor or profile was found to characterize Crohn's disease patients. Others have also considered this issue and concluded that the evidence is inconsistent in showing that IBD patients have greater psychological problems compared to other medically ill individuals $(20,21)$. Further, it has yet to be demonstrated that any psychological difficulties found in IBD patients precede the development of IBD symptoms. Studies suggesting this are all retrospective and based on either chart review or unstructured interviewing; assessment methods of questionable reliability. Thus, any observed problems might be the result, not the cause, of the symptoms $(11,22)$.

Furthermore, the assumption that psychosocial problems related to IBD are due to psychopathology can be harmful. Kurlander and O'Brien (22) suggest that such an approach contributes to discrimination against, and negative labelling of, the IBD patient. 
The consequences of this labelling include increased emotional distress, unhealthy coping, social rejection and isolation. Latimer (11) also criticized this approach, claiming that "... too much effort has been spent on trying to answer poorly framed and probably unanswerable questions...".

In conclusion, while individual studies have pointed to personality types associated with IBD, these studies are dated and methodologically weak. Review papers that consider multiple studies and more recent methodologically improved studies do not support the hypothesis that IBD is associated with specific personality factors, and certainly do not suggest that specific personality factors are causal. Without adequate data in support of this approach, and with the convincing argument that the assumption that IBD patients have personality defects leads to negative outcomes (discrimination, increased emotional distress, social rejection) (12), this approach should be abandoned.

\section{IBD AND \\ PSYCHIATRIC ILLNESS}

The data to suggest that IBD is based on psychological abnormalities are largely without foundation; however, this does not mean that psychological factors are irrelevant. It may be that there is a correlation between psychiatric illness and IBD. Following this approach, studies have examined IBD patients for the presence of psychiatric disorders. Whybrow et al (18) reported a psychiatric morbidity rate of $62.5 \%$ in their sample of Crohn's disease patients, the most common problem being depression. McKegney et al (12) reported that $40 \%$ of their sample of ulcerative colitis and Crohn's disease patients had psychiatric diagnoses. Clouse and Alpers (21) reviewed a number of studies examining the relationship between gastrointestinal illnesses and psychiatric conditions (defined by the Diagnostic and Statistical Manual, 3rd edn). They concluded that Crohn's disease patients - but not ulcerative colitis patients - are at a higher risk for major depression, compared with medically ill controls. Similar results using struc- tured interviewing have also been reported (23-26). Further, it has been suggested that increased depression might account for the lower quality of life of Crohn's disease patients (1).

If one accepts that psychiatric illness could have a negative effect on medical treatment, by directly affecting quality of life and indirectly affecting factors such as adherence, then standard psychiatric interventions (eg, antidepressant, anxiolytic or antipsychotic medication) could be administered to patients who meet the criteria for a psychiatric disorder. Treatment could be implemented by the gastroenterologist, possibly with consultation to a psychiatrist (for uncomplicated cases), or a referral could be made to a psy. chiatric service (for more complicated or severe cases). While this approach may be useful for the treatment of the subgroup of IBD patients with concomitant psychiatric disorders, it does not guide the treatment of IBD patients without psychiatric disorders. The value of this approach is therefore directly related to the prevalence of psychiatric conditions in IBD patients.

Blanchard et al (20) reported that the prevalence of psychiatric disorders in IBD patients was no different from that in a normal control group. An overall prevalence rate of $25 \%$ was reported in their sample, suggesting that psychiatric disorders among IBD patients is not common. Others who have reported a higher incidence of psychiatric disturbance among IBD patients $(12,18)$ suggest that mild forms of depression or anxiety (not major psychiatric disorders) are most common. Further, it must be assumed that standard psychiatric treatments will be as effective in IBD patients with a psychiatric disorder as in non-IBD psychiatric patients. It may be that concomitant IBD symptoms interfere with standard psychiatric treatment (eg, IBD patients might be less receptive to a psychiatric approach, they might be less adherent to psychiatric treatment, or they might experience side-effects from psychiatric medications that impact negatively on their gastrointestinal disease). Additional research is needed with respect to the appropriate psychiatric treatment for this subgroup of patients, but for now psychiatric consultation and treatment would be appropriate for this subgroup.

The correlation between psychiatric illness and IBD does not address the issue of causality. There is no evidence to suggest that patients with psychiatric illness are more prone to develop IBD than those without psychiatric illness. Data on whether psychiatric illness is more common among patients with IBD are inconsistent. Some investigators claim psychiatric illness as a significant risk factor (12,23-26), and others suggest that the rate of psychiatric illness in IBD is no higher than in the general population $(19,20)$. It is true that IBD can be a major life stressor, and for a subgroup this stress might produce symptoms sufficient for a psychiatric diagnosis.

\section{PSYCHOSOCIAL \\ CONSEQUENCES OF IBD}

Recent data suggest that psychosocial difficulties associated with IBD are the direct result of the symptoms of the disease, and not the cause of the disease (22). Therefore, patients' experience of their illness, and factors that influence this experience, should be identified and managed. Engel (27) proposed a biopsychosocial model to help identify specific factors that determine the experience of illness. In this model, biological (ie, disease), psychological and social factors are proposed to interact to effect illness experience. The assumption is that these factors apply to all IBD patients, to a greater or lesser degree. Therefore, it is important to assess each patient for the presence of difficulties in these areas (9).

A number of relevant psychosocial factors should be considered when assessing the illness experience of IBD patients. As argued by Garrett and Drossman (1) the way in which a patient (and others) experience illness has more to do with how well a patient feels than objective disease activity markers would predict $(1,6-8,22)$. Recent approaches with other chronic illnesses have led to the development of quality of life measures to assess more objectively these subjective feelings. Along these lines, an IBD-specific 
quality of life measure has been developed, the 'inflammatory bowel disease questionnaire' (28). Initial evaluation of this scale is encouraging, and suggests that it is sensitive to changes in disease activity over time.

Psychological distress: Increasing evidence indicates that IBD can be the cause, not the result, of psychosocial difficulties $(1,6-8,22)$. In particular, IBD can produce psychological distress that impairs quality of life. Mitchell et al (29) interviewed ulcerative colitis and Crohn's disease patients, examining complaints of primary bowel symptoms, general systemic symptoms, as well as emotional, functional and social impairment. They report that primary bowel and systemic symptoms, along with emotional impairment, were common problems identified by both patient groups. Fifty per cent of patients spontaneously reported feelings of depression, $44 \%$ reported frustration and $41 \%$ reported difficulty with work/ school attendance.

Sorensen et al (30) interviewed a group of Crohn's disease patients, and compared them with patients with acute medical problems. The two groups could not be differentiated on social, physical, employment or sick time variables. However, $54 \%$ of the Crohn's disease patients reported that disease exacerbations impaired their personal or professional lives. Using the 'sickness impact profile' (31), Drossman et al $(7,8)$ documented that Crohn's disease had a negative impact on overall psychosocial functioning, and a specific negative impact on social interaction, emotional behaviour, and sleep and rest. These data are not isolated findings, and collectively they indicate that the experience of IBD itself is associated with psychological distress $(1,6-8,16$, $22,32,33$ ).

Interrelationship between IBD and stress: Apart from the psychological distress associated with IBD and its symptoms, there has been limited attention given to other psychosocial factors. Several studies produced results suggesting that stressful life events are related to the onset, or exacerbation, of Crohn's disease symptoms $(10,12,18)$. Garrett et al (34) collected measures of stress (daily hassles) and IBD signs and symptoms daily for 28 days. Betweensubjects analyses showed a significant relationship between daily stress and symptom experience (ie, greater stress increased symptoms). Within-subjects analyses indicated that strong stresssymptom associations held for only three of the 10 subjects. In conjunction with other studies $(10,12,18)$ these data suggest that stressors can impact on the symptom experience of at least some Crohn's disease patients. The possibility that stress would precede symptom exacerbation was evaluated by North et al (35). They had Crohn's disease and ulcerative colitis patients keep monthly measures of stressful life events, depressed mood and symptom experience (disease activity) over a two year period. Gastroenterological assessment occurred at least twice per year. By identifying episodes of symptom relapse, they were able to statistically evaluate whether increased stress or depression, preceded relapse. Their data failed to support the hypothesis that increased stress or depression precipitated symptom flare-up.

Employment status and IBD: The possible effects of IBD symptomatology on employment is significant. Impaired employability would not only affect psychological well-being, but could reduce an individual's ability to pay for expensive medical treatment. Wyke and colleagues (36) studied the employment experiences of 144 IBD patients over six years in England. They reported that $72 \%$ of the patients were working, and $57 \%$ had maintained the same job over the period of study. However, over the same period $50 \%$ of the patients reported making modifications in their work primarily due to bowel disease. In a study of Danish Crohn's disease patients, Sorenson et al (31), reported that $65 \%$ were employed and of these, only $28 \%$ took more than 10 sick days in the previous year. Sonnenberg (37) reported on the frequency of disability in Germany for patients with IBD from 1982-86. He found that disability from Crohn's disease in women was twice that found in men but was similar in both sexes with ulcerative colitis. Compared with other diseases, both Crohn's disease and ulcerative colitis caused more patients under the age of 40 to be disabled. This finding has serious socioeconomic implications for those with IBD, which is compounded by the finding that 'white collar' workers were more often affected by IBD than 'blue collar' workers (37). A recent Canadian study (38) reported that $50 \%$ of Crohn's disease patients and $60 \%$ of ulcerative colitis patients did not miss any time from work. At the same time, however, $20 \%$ of the Crohn's disease patients and $15 \%$ of the ulcerative colitis patients lost more than four weeks of work in one year. Thus, it appears that the majority of IBD patients is able to maintain employment but a small percentage has significant difficulties. This may inappropriately suggest to employers that IBD patients, as a group, are a poor risk, thus increasing stress levels in many patients.

Gazzard et al (16) also examined employment status in their study of Crohn's disease patients. Although they were unable to demonstrate a correlation between work record and disease activity (including the number of surgeries), they found a correlation between work record and patients' level of anxiety. These data suggest that, as with disease status, disease activity alone is a poor predictor of how patients will cope with their disease and it may be that Crohn's disease and ulcerative colitis patients with poor work records may have more psychological distress than other equally ill IBD patients.

While these studies are informative, additional research is needed to evaluate the degree to which IBD interferes with work goals or satisfaction. Issues such as ability to get insurance, promotion, or taking less demanding or satisfying jobs in order to reduce stress need to be examined.

\section{SUMMARY}

This article examined a number of perspectives on the role of psychosocial factors in IBD. This area of enquiry has clearly evolved over the years. Initially, there was an attempt to demonstrate that IBD patients suffered from psychopathology; the implication being that 
such psychopathology was causal. This approach has largely been abandoned, however, due to insufficient scientific support. The prevailing view is that IBD is a significant stressor that can seriously compromise a patient's quality of life and, in some cases, result in psychiatric disturbance. Viewing psychosocial adjustment in IBD from a quality

\section{REFERENCES}

1. Garrett JW, Drossman DA. Health status in inflammatory bowel disease: Biological and behavioural considerations. Gastroenterology 1990;99:90-6.

2. Best WR, Becktel JM, Singleton JW, et al. Development of a Crohn's Disease Activity Index. Gastroenterology 1976;70:439-44

3. Van Hees PAM, Van Elteren PH, Van Lier HJJ, Van Tongeren JHM. An index of inflammatory activity in patients with Crohn's disease. Gut 1980;21:279-86.

4. Powell-Tuck J, Bonn RL, LennardJones JE. A comparison of oral prednisolone given as single or multiple daily doses for active proctololitis. Scand J Gastroenterol 1989;13:833-7.

5. Truelove SC, Witts LJ. Cortisone in ulcerative colitis: Final report on a therapeutic trial. Br Med J 1955;2:1041-8.

6. Drossman DA, Patrick DL, Mitchell CM, Zagami EA, Applebaum MI. Health related quality of life in inflammatory bowel disease. Dig Dis Sci 1989;34:1379-86.

7. Drossman DA, Mitchell CM, Applebaum MI, Patrick DL, Zagami EA. Clinical and psychosocial features of CD and GUC: A study of the NFIC membership. Gastroenterology 1989;96:A129.

8. Drossman DA, Leserman J, Mitchell CM, Li Z, Zagani EA, Patrick DL. Psychosocial and disease predictors of utilization in IBD. Gastroenterology 1990:98:A167.

9. Vallis TM, Turnbull GK. Clinical management of inflammatroy bowel disease: Beyond disease activity. Part II. Strategies for maximizing psychoscial health. Can J Gastroenterol. (In press)

10. Gerbert B. Psychological aspects of Crohn's disease. J Behav Med 1980;3:41-58.

11. Latimer PR. Crohn's disease: A review of the psychological and social outcome. Psychol Med 1987;8:649-56. 12. McKegney FP, Gordon RO, Levine of life perspective is seen as the most accurate and responsible perspective for the following reasons. First, it can account for all of the various ways in which IBD can interfere with functioning (eg, psychological, social, vocational). Second, it can take into consideration the degree of impairment, ranging from occasional minor distress to full-blown

SM. A psychosomatic comparison of patients with ulcerative colitis and Crohn's disease. Psychosom Med 1970;32:153-66.

13. Ford CV, Globen GA, CastelnuovoTedesco P. A psychiatric study of patients with regional enteritis. JAMA 1969;208:311-5.

14. Cohn EM, Lederman II, Shore E. Regional enteritis and its relation to emotional disorders. Am J Gastroenterol 1977;54:378-87.

15. Parfitt HL. Psychiatric aspects of regional enteritis. Can Med Assoc ] 1967;97:807-11.

16. Gazzard BG, Price HL, Libby GW Dawson AM. The social toll of Crohn's disease. Br Med J 1978;2:1117-9.

17. Crocket RW. Psychiatric findings in Crohn's disease. Lancet 1952;i:946-9.

18. Whybrow PC, Kane FJ, Lipton MA. Regional ileitis in psychiatric disorder. Psychosom Med 1968;30:209-21

19. Whitehead WE, Bosmajian LS. Behavioural medicine approaches to gastrointestinal disorders. J Consult Clin Psychol 1982;50:972-83.

20. Blanchard EB, Scharff L, Schwarz SP, Suls JM, Barlow DH. The role of anxiety and depression in irritable bowel syndrome. Behav Res Ther 1990;28:401-5.

21. Clouse RE, Alpers DH. The relationship of psychiatric disorder to gastrointestinal illness. Ann Rev Med 1986;37:283-95,

22. Kurlinder KA, O'Brien MF. Psychosocial issues, In: Peppercorn MA, ed. Therapy of Inflammatory Bowel Disease: New Medical and Surgical Approaches. New York: Dekker, 1990:243-65.

23. Andrews H, Barczak P, Allan RN. Psychiatric illness in patients with inflammatory bowel disease. Gut 1987;28:1600-4.

24. Goldberg D. A psychiatric study of patients with diseases of the small intestine. Gut 1970;11:459-65.

25. Helzer JE, Shammas S, Norland CC, Stillings WA, Alpers DH. A study of the association between Crohn's disease and psychiatric illness. and serious psychiatric disorder. Third, it avoids the pejorative aspect of some of the alternative perspectives, such as the notion that IBD patients are, by definition, psychopathological. In part II of this series, specific strategies to guide the gastroenterologist in the assessment and management of psychosocial factors are presented (9).

Gastroenterology 1984;86:324-30.

26. Tartar RE, Switala J, Carra J, Edwards KL, Van Thiel DH. Inflammatory bowel disease: Psychiatric status of patients before and after disease onset. Int J Psychiatry Med 1987;17:173-81.

27. Engel $G$. The need for a new medical model: A challenge for biomedicine. Science 1977;196:129-36.

28. Guyatt G, Mitchell A, lrvine EJ, et al. A new measure of health status for clinical trials in inflammatory bowel disease. Gastroenterology 1989:96:804-10.

29. Mitchell A, Guyatt G, Singer J, et al. Quality of life in patients with inflammatory bowel disease. J Clin Gastroenterol 1988;10:306-10.

30. Sorensen VZ, Olson BG, Binder V Life prospects and quality of life in patients with Crohn's disease. Gut 1987;28:382-5.

31. Berger, M, Bobbitt RA, Pollard WE, Martin DP, Gilson DS. The sickness impact profile: Validation of a health status measure. Med Care 1976;14:57-67.

32. Mallett SJ, Lennard-Jones JE, Bingley J, Gilan E. Colitis. Lancet 1978;ii:619-21

33. Gazzard BG. The quality of life in Crohn's disease. Gut 1987;28:378-81.

34. Garrett VD, Brantley PJ, Jones GN, $\mathrm{McNight} \mathrm{GT}$. The relation between daily stress and Crohn's disease. J Behav Med 1991;14:87-96.

35. North CS, Alpers TH, Helzer JE, Spitznagel EL, Clouse RE. Do life events or depression exacerbate inflammatory bowel disease? A prospective study. Ann Intern Med 1991;114:381-6.

36. Wyke RJ, Edward FC, Allan RN. Employment problems and prospects for patients with inflammatory bowel disease. Gut 1988;29:1229-35.

37. Sonnenberg A. Disability from inflammatory bowel disease among employees in West Germany. Gut 1989;30:367-70.

38. Pinchek BR, Kirdeikis J, Thomson ABR. Economic impact of inflammatory bowel disease in Alberta. Can J Gastroenterol 1988;2:53-6. 


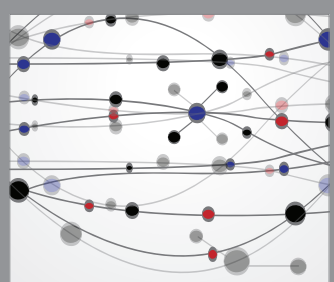

The Scientific World Journal
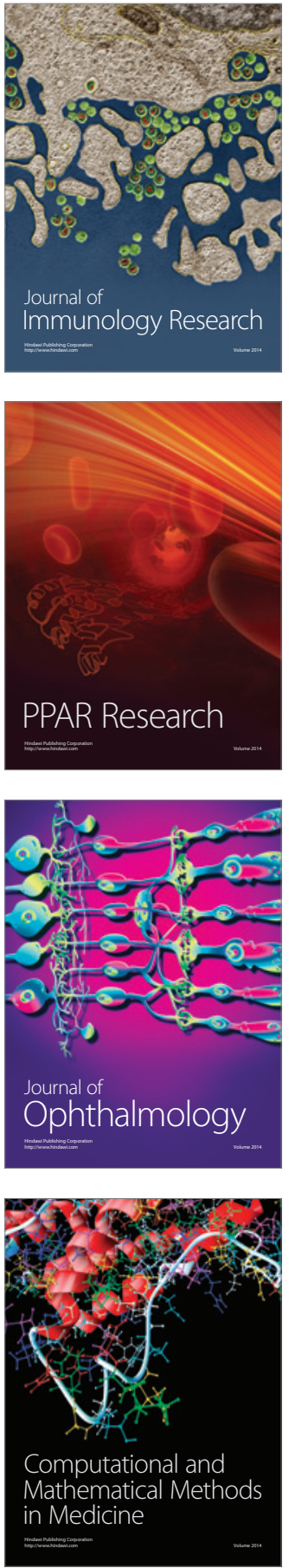

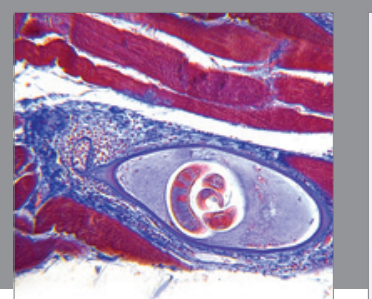

Gastroenterology Research and Practice

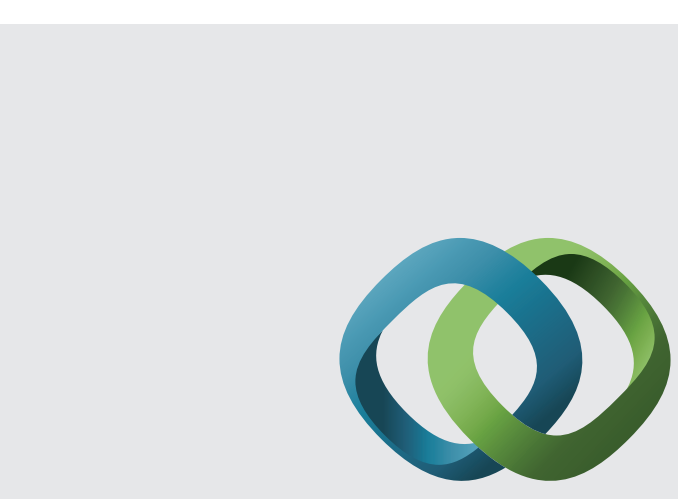

\section{Hindawi}

Submit your manuscripts at

http://www.hindawi.com
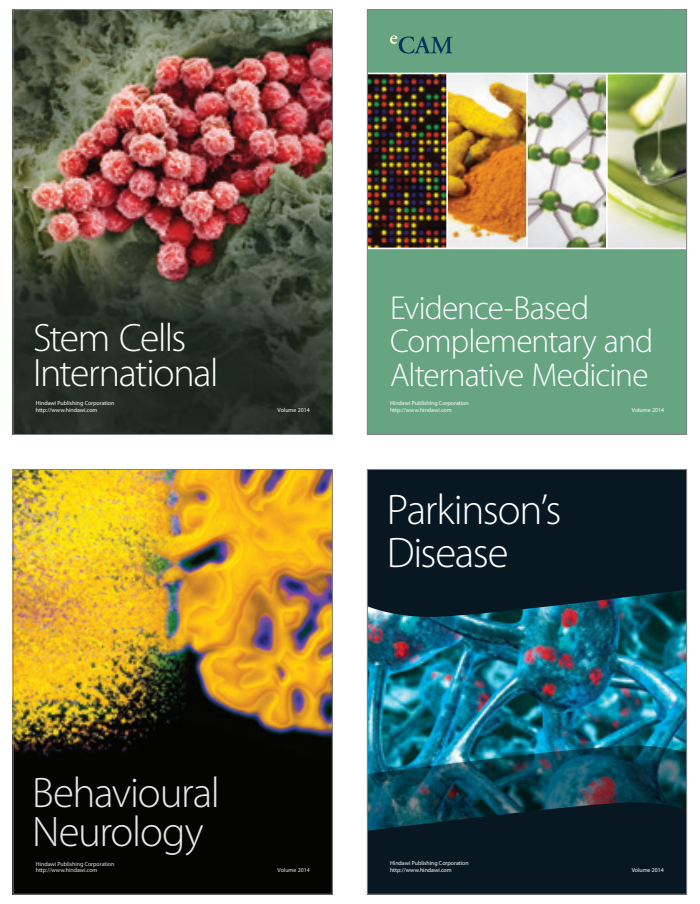
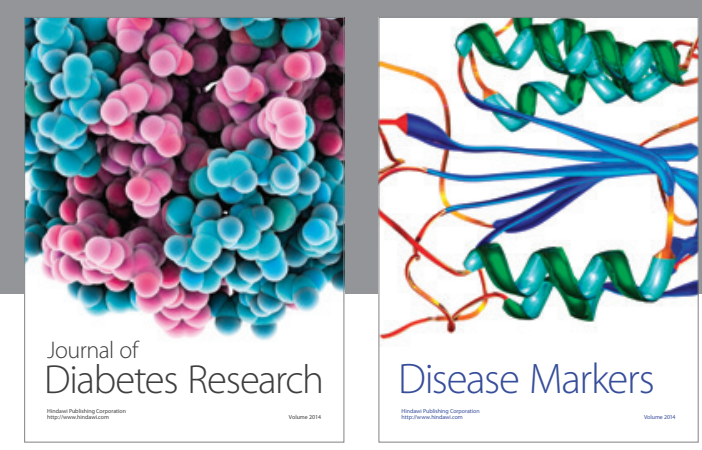

Disease Markers
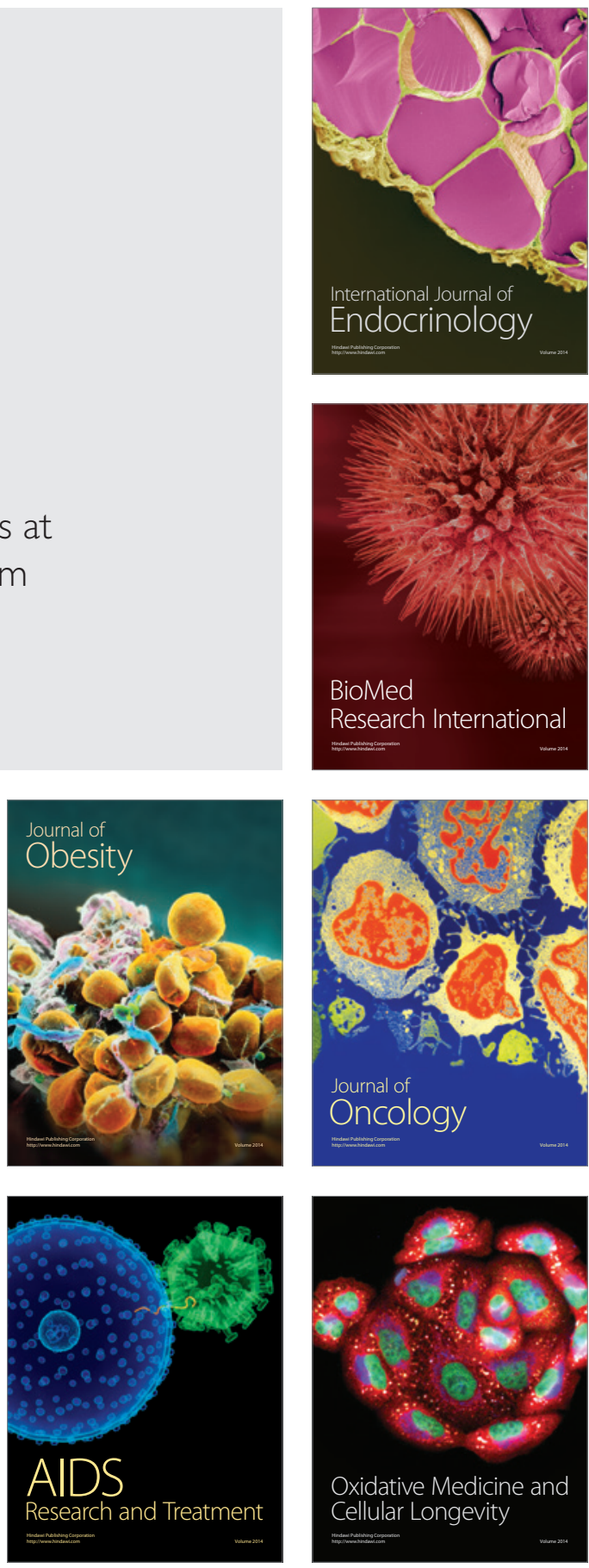